\title{
High Performance Liquid Chromatography of Phosphomolybdate and Silicomolybdate: Simultaneous Determination of Phosphate and Silicate
}

\author{
Ichiro KoshushI and Toshio ImanarI \\ Faculty of Pharmaceutical Sciences, Chiba University, Yayoi-cho, Chiba 260
}

\begin{abstract}
A method for the simultaneous determination of phosphate and silicate was established by high performance liquid chromatography as their molybdocomplexes. The excellent separation of them was performed on a column packed with Styragel $60 \AA$ (Waters Associates, Inc.) using an aqueous $55 \%(\mathrm{v} / \mathrm{v}$ ) acetonitrile solution containing $0.75 \mathrm{M}$ sulfuric acid and $0.02 \mathrm{M}$ tetrabutylammonium hydrogensulfate as an elvent. The calibration curves for phosphate and silicate were linear in the range $0.03-10 \mu \mathrm{gP} / \mathrm{ml}$ and $0.01-5.0 \mu \mathrm{gSi} / \mathrm{ml}$, respectively. The method was applied to the determination of phosphate and silicate in human urine and plasma.
\end{abstract}

Keywords High performance liquid chromatography, phosphate, silicate, phosphomolybdate, silicomolybdate

Phosphorus and silicon are essential elements for organisms and exist in part as phosphate and silicate which may play very important roles biologically. ${ }^{1-4}$ Therefore, phosphate and silicate in biological materials have been determined by colorimetry depending on the formation and reduction of molybdocomplexes. $^{5-10}$ These molybdenum blue methods are convenient for routine work and used in the clinical laboratories, but they are not so sensitive and accurate because of the formation of a few unstable colored products.

Besides molybdenum blue methods, molybdenum yellow methods ${ }^{11-13}$ have been applied to the determination of phosphate and silicate in environmental samples. However, in the determination of phosphate and silicate in biological materials, these methods are apt to be interfered by the components having strong absorbance in UV-region.

This paper describes the separation of phosphomolybdate $(\mathrm{P}-\mathrm{Mo})$ and silicomolybdate $(\mathrm{Si}-\mathrm{Mo})$ by high performance liquid chromatography (HPLC) and its application to the simultaneous determination of phosphate and silicate in biological materials such as human urine and plasma.

\section{Experimental}

\section{Reagents}

Acetonitrile and methanol for HPLC were purchased from Wako Pure Chemicals. Tetrabutylammonium hydrogensulfate (TBA) was purchased from Tokyo Kasei Kogyo Co., Ltd. All other chemicals were of reagent grade and reagent solutions were prepared by dissolving in deionized and distilled water. Styragel 60
$\AA$ and Styragel $100 \AA$ were purchased from Waters Associates, Inc. Bio-Beads SX-2 and TSK gel LS-111 were obtained from Bio-Rad Laboratories and Toyo Soda Co. Ltd. The standard solution of phosphate was prepared from potassium phosphate(monobasic) by dissolving in distilled water. The standard solution of silicate $(1000 \mu \mathrm{g} / \mathrm{ml}$ as $\mathrm{Si})$ for absorption spectrophotometry (Wako Pure chemicals) was used by diluting the solution with distilled water before use.

The reagent solution of $1.0 \%(w / v)$ ammonium molybdate was prepared by dissolving $1.0 \mathrm{~g}$ of ammonium molybdate in $100 \mathrm{ml}$ of $0.2 \mathrm{M}$ sulfuric acid. The solution was stored in a plastic bottle at room temperature in the dark.

\section{Apparatus and chromatographic conditions}

The high performance liquid chromatographic system used consisted of a reciprocating pump (PSU-2.5, Seishin Seiyaku Co. Ltd., Tokyo), a loop injector (VMU-5, Seishin Seiyaku Co. Ltd., Tokyo), UVdetector (UVILOG-7, Oyo-Bunko Kiki Co. Ltd., Tokyo) and recorder (SS-250F, Sekonic, Tokyo). A pyrex glass tube $(5 \mathrm{mmI}$.D. $\times 200 \mathrm{~mm})$ was packed with Styragel $60 \AA$. P-Mo and Si-Mo were detected at 310 $\mathrm{nm}$ which is their absorption maxima.

The eluent, $55 \%(\mathrm{v} / \mathrm{v}) \mathrm{CH}_{3} \mathrm{CN}-0.75 \quad \mathrm{M} \mathrm{H}_{2} \mathrm{SO}_{4}-20$ $\mathrm{mM}$ TBA, was prepared as follows: $6.79 \mathrm{~g}$ of tetrabutylammonium hydrogensulfate was dissolved in $250 \mathrm{ml}$ of $3.0 \mathrm{M}$ sulfuric acid and then $550 \mathrm{ml}$ of acetonitrile was added. The solution was made up to 11 with deionized distilled water.

\section{Assay procedure}

Molybdocomplexes of phosphate and silicate were formed by adding $500 \mu \mathrm{l}$ of $0.2 \mathrm{M}$ sulfuric acid 
containing $1.0 \%$ ammonium molybdate to $500 \mu \mathrm{l}$ of sample solution. After $30 \mathrm{~min}, 1.0 \mathrm{ml}$ of aqueous $66 \%(\mathrm{v} / \mathrm{v})$ acetonitrile solution containing $0.6 \mathrm{M}$ sulfuric acid was added and the solution was submitted to HPLC.

Analysis of plasma. Five hundred microliter of plasma was placed in a centrifuge tube and $2 \mathrm{ml}$ of chloroform and $500 \mu \mathrm{l}$ of $10 \%(\mathrm{w} / \mathrm{v})$ trichloroacetic acid(TCA) were added. After shaking vigorously, it was centrifuged at $2000 \times g$ for $5 \mathrm{~min}$. The supernatant $(500 \mu \mathrm{l})$ was transferred to a plastic tube, followed by the addition of $10 \mu \mathrm{l}$ of $10 \%$ bromine in ethanol and molybdocomplexes were prepared by the procedure described above.

Analysis of urine. Urine sample $(500 \mu \mathrm{l})$ diluted 25 times with distilled water was placed in a plastic tube and molybdocomplexes were prepared in the same manner as for plasma samples.

\section{Molybdenum blue methods}

Determination of phosphate in human urine was done according to the procedure of the molybdenum blue method achieved by Fiske and SubbaRow ${ }^{5}$, and silicate in human urine according to the procedure of the molybdenum blue method of Baumann. ${ }^{9}$

\section{Results and Discussion}

\section{Separation of molybdocomplexes}

One of the major problems concerned with the chromatographic separation of $\mathrm{P}-\mathrm{Mo}, \mathrm{Si}-\mathrm{Mo}$ and excess reagent, molybdate, originates from the dissociatability of molybdocomplexes in the eluent. Especially, P-Mo dissociates reversibly and $\mathrm{Si}-\mathrm{Mo}$ is present almost irreversibly. This is the reason why miscible organic solvent with water has to be used as a component of the eluent. Figure 1 shows that $\mathbf{P}-\mathrm{Mo}$ is

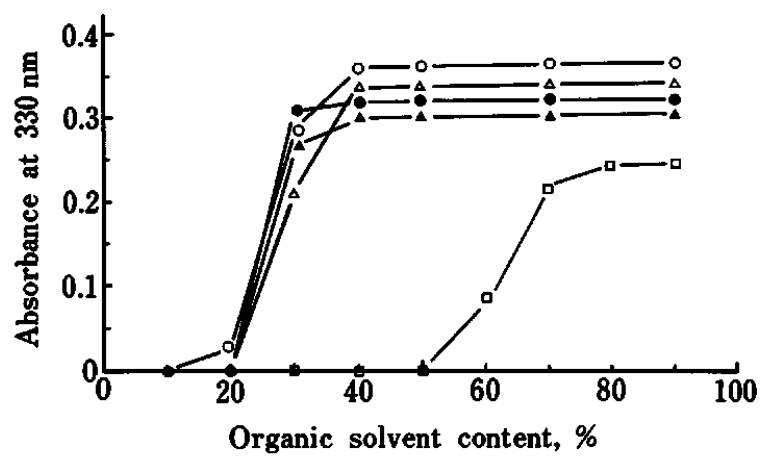

Fig. 1 Effect of organic solvents on the stabilization of phosphomolybdate. The solution containing P-Mo $(100 \mathrm{\mu g} / \mathrm{ml}$ as $\mathrm{P})$ and $0.4 \%$ molybdate was diluted 100 times with the aqueous solution containing $0.45 \mathrm{M}$ $\mathrm{H}_{2} \mathrm{SO}_{4}$ and organic solvent $(\mathrm{MeOH}(\square), \mathrm{EtOH}(\Delta)$, $\operatorname{PrOH}(\triangle), \mathrm{CH}_{3} \mathrm{CN}(O)$ and dioxane(O)). P-Mo was detected at $330 \mathrm{~nm}$ at which the absorbance of molybdate (blank) was low. scarcely dissociated in the eluent which contains methanol, ethanol, propanol, dioxane or acetonitrile.

Separation of these complexes was investigated by ion pair-reversed phase high performance liquid chromatography (IP-RPHPLC) using styrene-divinylbenzene(DVB) copolymers such as Amberlite XAD-2, Bio-Beads SX-2, TSK gel LS-111, Styragel $60 \AA$ and Styragel $100 \AA$. Organic solvents examined were methanol, ethanol, propanol, dioxane and acetonitrile. The separation of these complexes was achieved successfully by IP-RPHPLC system using Styragel 60 $\AA$ as a packing material and $55 \%(\mathrm{v} / \mathrm{v}) \mathrm{Ch}_{3} \mathrm{CN}-0.75$ $\mathrm{M} \mathrm{H}_{2} \mathrm{SO}_{4}-20 \mathrm{mM}$ TBA as the eluent. A typical chromatogram is shown in Fig. 2.

Though both $\mathrm{Si}-\mathrm{Mo}$ and $\mathrm{P}-\mathrm{Mo}$ in general form slightly soluble ternary complexes with quarternary ammonium, ternary complexes with TBA are soluble in aqueous acetonitrile solution containing more than $50 \%(\mathrm{v} / \mathrm{v})$. When an aqueous sample containing molybdocomplexes was introduced into flow stream of the eluent by a loop sampler, ternary complexes of molybdocomplexes formed with TBA were precipitated due to the decrease of acetonitrile content at interface between the eluent and an aqueous sample. This is the reason why acetonitrile was added to the aqueous solution containing molybdocomplexes.

\section{Effect of the acetonitrile content}

In IP-RPHPLC used styrene-DVB copolymer as a packing material, the acetonitrile content affects the capacity factor $(k)$ for molybdocomplexes. The capacity factor of P-Mo decreased significantly with the increase of acetonitrile content in the eluent, but those of molybdate and $\mathrm{Si}-\mathrm{Mo}$ scarcely decreased. At a lower content than $50 \%(\mathrm{v} / \mathrm{v}), \mathrm{P}-\mathrm{Mo}$ and $\mathrm{Si}-\mathrm{Mo}$ formed

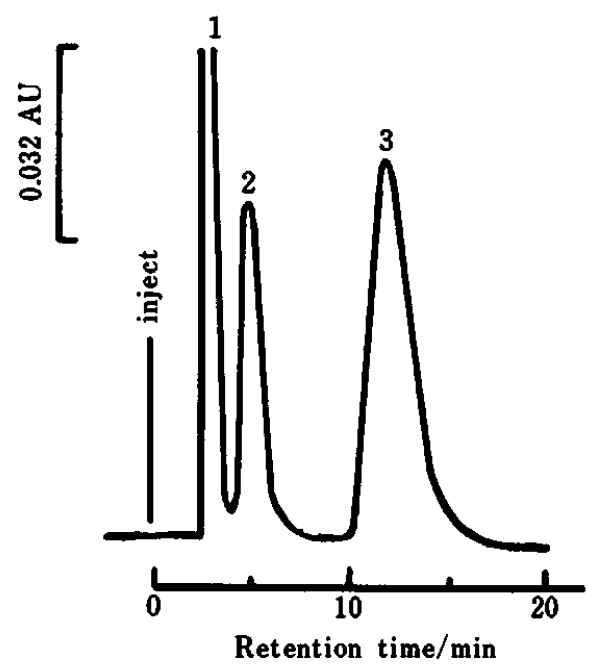

Fig. 2 Separation of phosphomolybdate and silicomolybdate by HPLC. 1, Molybdate; 2, Si-Mo; 3, P-Mo. Column, styragel 60 A (5 mm I.D. $\times 200 \mathrm{~mm}$ ); eluent, $55 \%$ (v/v) $\mathrm{CH}_{3} \mathrm{CN}-0.75 \mathrm{M} \mathrm{H}_{2} \mathrm{SO}_{4}-20 \mathrm{mM}$ TBA; flow rate, $1.0 \mathrm{ml} / \mathrm{min}$; sample size, $50 \mu \mathrm{l}$; detection, $310 \mathrm{~nm}$. 
slightly soluble ternary complexes with TBA.

\section{Effect of the concentration of sulfuric acid}

The concentration of sulfuric acid affects the capacity factor for molybdocomplexes. The capacity factor of P-Mo decreased significantly with the increase of concentration of sulfuric acid, but those of $\mathrm{Si}-\mathrm{Mo}$ and molybdate were scarcely affected by the concentration of sulfuric acid.

\section{Effect of the concentration of $T B A$}

The capacity factor of molybdocomplexes is shown in Fig. 3 as a function of the concentration of the TBA in aqueous $55 \%(v / v)$ acetonitrile solution containing $0.75 \mathrm{M}$ sulfuric acid as an eluent. Capacity factors of $\mathrm{P}-\mathrm{Mo}$ and $\mathrm{Si}-\mathrm{Mo}$ increased with the increase in the concentration of TBA as an ion pair reagent, and that of $\mathrm{P}-\mathrm{Mo}$ reached a maximum at $20 \mathrm{mM}$ TBA. In the concentration higher than $20 \mathrm{mM}$ TBA, the elution profile of the three species was not reproducible.

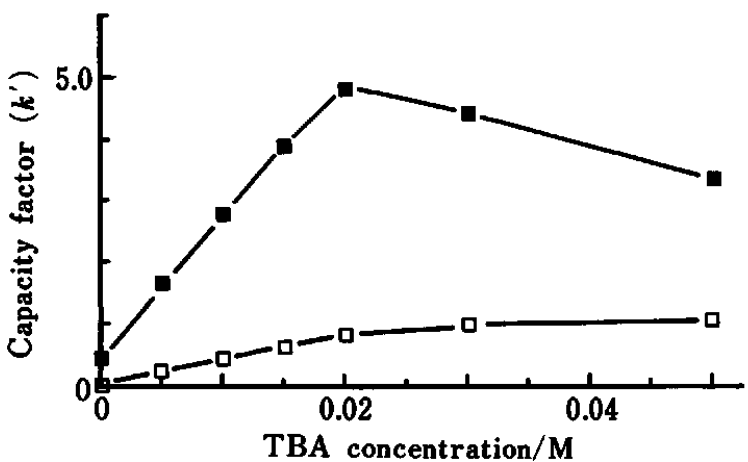

Fig. 3 Capacity factors of phosphomolybdate and silicomolybdate vs. TBA concentration. $\square, \mathrm{P}-\mathrm{Mo} ; \square, \mathrm{Si}-$ Mo; eluent, 55\% (v/v) $\mathrm{CH}_{3} \mathrm{CN}-0.75 \mathrm{M} \mathrm{H}_{2} \mathrm{SO}_{4}$-TBA. Other chromatographic conditions are as in Fig. 2.

Table 1 Effect of foreign substances on the determination of phosphate and silicate

\begin{tabular}{|c|c|c|c|}
\hline \multicolumn{2}{|c|}{ Substance } & \multicolumn{2}{|c|}{ Recovery, $\%$} \\
\hline - & - & 100 & 100 \\
\hline $\mathrm{NaCl}$ & $10 \mathrm{mg} / \mathrm{ml}$ & 98.3 & 102 \\
\hline KI & $10 \mathrm{mg} / \mathrm{ml}$ & 87.1 & 12.7 \\
\hline $\mathrm{NaF}$ & $10 \mathrm{mg} / \mathrm{ml}$ & 0.0 & 0.0 \\
\hline $\mathrm{CaCl}_{2}$ & $10 \mathrm{mg} / \mathrm{ml}$ & 102 & 96.4 \\
\hline $\mathrm{H}_{2} \mathrm{O}_{2}$ & $10 \mathrm{mg} / \mathrm{ml}$ & 0.0 & 0.0 \\
\hline $\mathrm{Br}_{2}$ & $10 \mathrm{mg} / \mathrm{ml}$ & 102 & 100 \\
\hline Uric acid & $0.2 \mathrm{mg} / \mathrm{ml}$ & 89.4 & 28.1 \\
\hline Heparin & $0.1 \mathrm{mg} / \mathrm{ml}$ & 101 & 99.7 \\
\hline $\mathrm{H}_{2} \mathrm{SiO}_{3}$ & $10 \mu \mathrm{g} / \mathrm{ml}$ as $\mathrm{Si}$ & - & 100 \\
\hline $\begin{array}{l}\mathrm{H}_{2} \mathrm{PO}_{4} \\
\mathrm{H}_{4} \mathrm{P}_{2} \mathrm{O}_{7}\end{array}$ & $\begin{array}{l}10 \mu \mathrm{g} / \mathrm{ml} \text { as } P \\
10 \mu \mathrm{g} / \mathrm{ml} \text { as } \mathrm{P}\end{array}$ & $\begin{array}{l}98.4 \\
100\end{array}$ & - \\
\hline
\end{tabular}

$\mathrm{P} / \mathrm{Mo}(1.0 \mu \mathrm{gP} / \mathrm{ml})$ and $\mathrm{Si}-\mathrm{Mo}(1.0 \mu \mathrm{gSi} / \mathrm{ml})$ were formed in $0.1 \mathrm{M} \mathrm{H}_{2} \mathrm{SO}_{4}$ aqueous solution containing $0.4 \%$ ammonium molybdate and foreign substance.

\section{Influence of foreign substances}

Table 1 shows that the present method is interfered by a few foreign substances. Reducing substances such as uric acid and potassium iodate interfered with the present method by reducing the P-Mo. The reduced $\mathbf{P}$-Mo was eluted earlier than $\mathbf{P}-\mathbf{M o}$ under the conditions of HPLC given in Fig. 2. Hydrogen peroxide couldn't be used for the prevention of interference from reducing substances, because it oxidized molybdate to yellow peroxymolybdate ${ }^{14}$, which did not form molybdocomplexes with phosphate and silicate. Then, bromine was used as an oxidizing agent because it did not oxidize the molybdate.

Sodium fluoride used in general as an antdicoagulant interfered with the present method, but heparin did not interfere.

\section{Precision}

In the operating conditions described above, the calibration curve for silicate was linear in the range $0.01-5.0 \mu \mathrm{gSi} / \mathrm{ml}$ and that for phosphate was linear in the range $0.03-10 \mu \mathrm{gP} / \mathrm{ml}$. By using the procedure described above, the limits of detection for phosphate and silicate were $0.01 \mu \mathrm{gP}$ and $0.005 \mu \mathrm{gSi} / \mathrm{ml}(S / N=2)$, respectively. When $0.5 \mu \mathrm{g} / \mathrm{ml}$ of phosphate and silicate were determined ten times by the recommended procedure, relative standard deviations(RSD) were 3.18 and $3.64 \%$, respectively.

\section{Analysis of urine and plasma}

Bromine was added excessively to diluted urine and deproteinized plasma for the oxidization of reducing materials as uric acid. Phosphate and silicate in the pretreated samples were determined according to the

Table 2 Recovery tests of silicate and phosphate from human urine and plasma

\begin{tabular}{|c|c|c|c|c|c|}
\hline \multicolumn{2}{|c|}{ Added $/ \mu \mathrm{g} \mathrm{ml} l^{-1}$} & \multicolumn{2}{|c|}{ Found/Mg ml-1 } & \multicolumn{2}{|c|}{$\begin{array}{c}\text { Recovery, } \% \\
\text { Si }\end{array}$} \\
\hline \multicolumn{6}{|l|}{ Urine } \\
\hline- & - & 12.5 & 320 & - & - \\
\hline 25.0 & 200 & 38.3 & 520 & 103 & 100 \\
\hline 50.0 & 400 & 62.4 & 728 & 99.8 & 102 \\
\hline \multicolumn{6}{|l|}{ Plasma } \\
\hline - & - & 1.21 & 21.4 & - & - \\
\hline 1.0 & 4.0 & 2.24 & 25.5 & 103 & 103 \\
\hline 2.0 & 8.0 & 3.16 & 29.9 & 97.4 & 106 \\
\hline
\end{tabular}

Table 3. Determination of silicate and phosphate in human urine and plasma

\begin{tabular}{|c|c|c|c|c|}
\hline \multirow{2}{*}{ Subject } & \multicolumn{2}{|c|}{ Urine $/ \mathrm{kg} \mathrm{ml} \mathrm{gl}^{-1}$} & \multicolumn{2}{|c|}{ 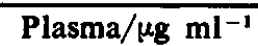 } \\
\hline & $\mathbf{S i}$ & $\mathbf{P}$ & $\mathbf{S i}$ & $\mathbf{P}$ \\
\hline $\mathbf{A}$ & 13.2 & 618 & 0.44 & 27.6 \\
\hline $\mathbf{B}$ & 14.6 & 470 & 0.44 & 38 \\
\hline C & 30.3 & 618 & 1.57 & 25.4 \\
\hline D & 15.9 & 540 & 0.96 & 34.1 \\
\hline $\mathbf{E}$ & 18.2 & 420 & 1.21 & 31.7 \\
\hline
\end{tabular}



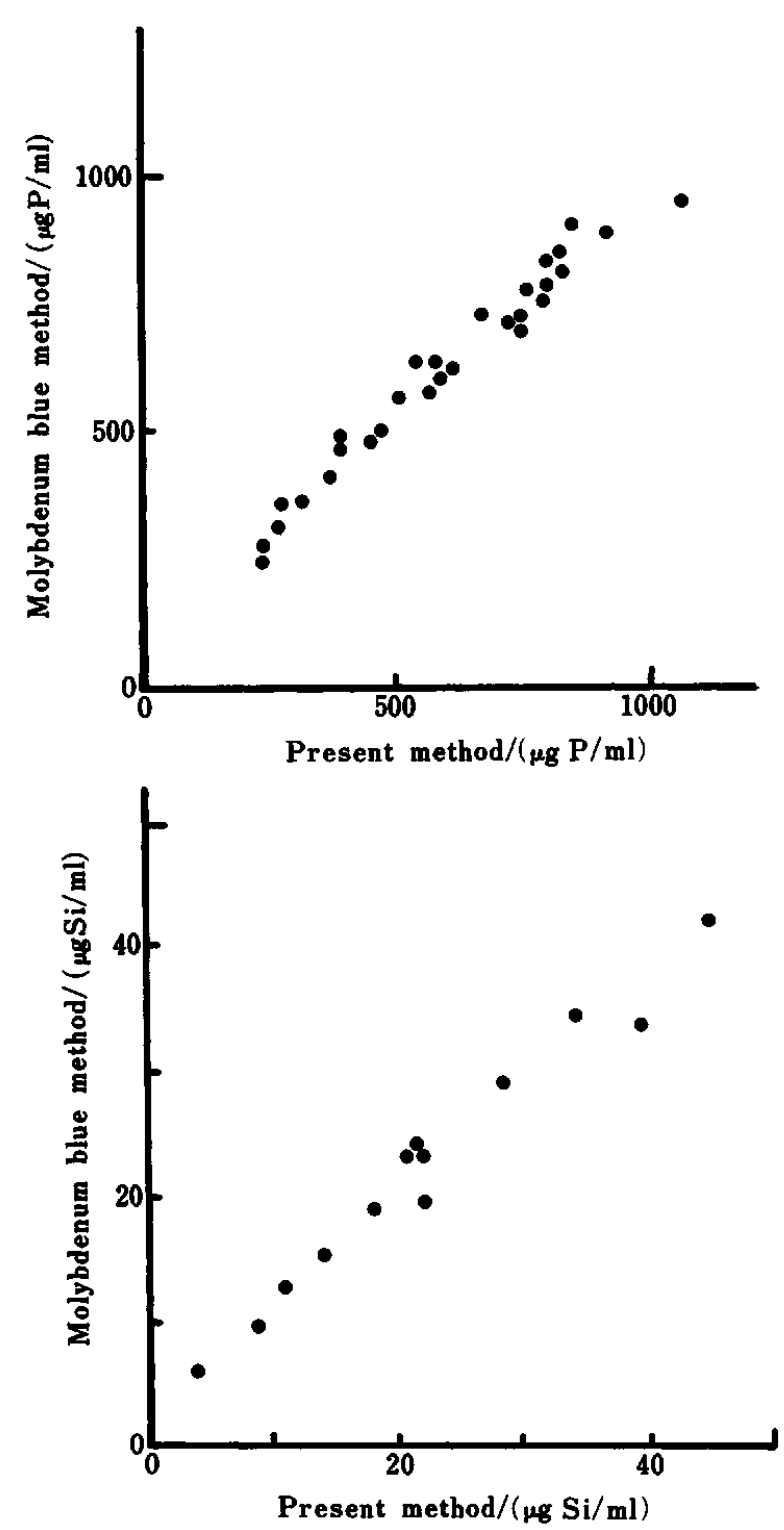

Fig. 4 Relationship between molybdenum blue methods and present method for determination of phosphate and silicate in human urine samples.

method described in the experimental section. The analytical results of recovery tests from urine and plasma are shown in Table 2. The recoveries of phosphate varied from 100 to $106 \%$ and those of silicate from 97.4 to $103 \%$.
Analytical results of phosphate and silicate in human urine and plasma are shown in Table 3.

The concentrations of silicate and phosphate in normal human urine measured by the present method $(x)$ were compared with those obtained by the molybenum blue methods ${ }^{5,9}(y)$. We found significant correlations: $r=0.990, y=0.883 x+3.92$ for silicate; $r=0.983, y=0.910 x+84.4$ for phosphate (Fig. 4). At low levels, values obtained by molybdenum blue methods were larger than those obtained by the present method for both phosphate and silicate.

It should be emphasized that the present method is more accurate than molybdenum blue methods, because the reaction product is single and stable in acidic aqueous solution.

Moreover, we will try to study physiological roles for silicate and phosphate in bone calcification processes by the use of this method.

\section{References}

1. T. H. McGavack, J. G. Leslie and K. T. Kao, Proc. Soc. Exp. Biol. and Med., 110, 215 (1962).

2. J. G. Leslie, K. Y. T. Kao and T. H. McGavack, Proc. Soc. Exp. Biol. and Med., 110, 218 (1962).

3. K. Schwarz, Proc. Nat. Acad. Sci. USA, 70, 1608 (1973).

4. E. M. Carlisle, Nutrition Reviews, 40, 193 (1982).

5. C. H. Fiske and Y. SubbaRow, J. Biol. Chem., 66, 375 (1925).

6. H. H. Taussky and E. Shorr, J. Biol. Chem., 202, 675 (1953).

7. O. H. Lowry and J. A. Lopez, J. Biol. Chem., 162, 421 (1946).

8. E. J. King and H. Stantial, Biochem. J., 27, 990 (1933).

9. H. Baumann, Hoppe Seyler's Z. Physiol. Chem., 319, 38 (1960).

10. M. Ihnat, Anal. Biochem., 124, 380 (1982).

11. J. K. Heinonen and R. J. Lahti, Anal. Biochem., 113, 313 (1981).

12. D. A. Bencini, J. R. Wild and G. A. O'Donovan, Anal. Biochem., 132, 254 (1983).

13. M. A. Munoz, M. Balon and C. Fernandez, Clin. Chem., 29, 372 (1983).

14. Y. Ogata and Y. Sawaki, Bull. Chem. Soc. Jpn., 36, 1453 (1963).

(Received April 12. 1985)

(Accepted May 24, 1985) 